\title{
ERTLRENZ I Experiences from scaling up a shop-in-shop system for mass customized high performance sports shoes
}

\author{
Sven Renz, ERTLRENZ GmbH \\ Dirk Rutschmann, René Pfeiffer, Florian Wild, corpus.e AG
}

\begin{abstract}
The mass customization of shoes is one area which is in the focus of the academic and practitioners discussion since the beginning of the emergence of the basic concepts. Since these days we observed many different projects in this industry with different approaches and success in scaling these projects onto a mass level. We show in this case study the key factors and experiences of replicating a best fit based mass customization concept in a well chosen area of the shoe market, mass customized skiing boots, where we concentrate on one of the mass customization possibilities of individual fit and eclipsing the other main feature of style.
\end{abstract}

Keywords: Mass Customization, Apparel \& Shoe Industry, 3D Footscanning, Case Study

\section{Introduction}

The shoe industry was always in the spotlight for the idea of bringing individualized products and mass production together to the consumer [Piller, 1999]. The appeal of the two additional features of fit and personal design combined with a shopping experience seemed for many researchers and practitioners as obvious as the right strategic answer for high quality producers not willing to compete only on a price basis. Different empirical studies showed that the consumer's perception of these additional possibilities outweighs a higher price and the delivery time compared to another standard product in the same category. Other researchers focused on the different costs along the value chain comparing mass customization and mass production [Anderson, 2004]. Following this strategy a few companies from totally different segments of the shoe industry like The Custom Foot, Creo Interactive, adidas, selve, leftfoot company, Otabo, Zazzle.com, prior2lever, Salomon custom fit, Pakerson or Carnac Cycling Shoes pioneered a mass customization offer in their markets. Even though mass customization in the shoe industry is in different shapes on the market since more than ten years now the locations to buy customized shoes are still sparse around the globe and not as projected in the early years.

On the other hand we see in some areas an overwhelming demand for customized shoes [Rutschmann, 2003]. The Munich based Sport Shop Ertl/Renz started in 2006 selling standard ski boots with the possibility to individualize these kinds of shoes to the customer's feet by the standard, hand crafted methods more or less like many other stores in the boot fitting scenery do. Because there is on the one hand a tremendous demand for customized ski boots represented by doubled sales each year and the highest sales rate in Germany for high quality ski boots in this shop (approx. 1.500 pairs per season) and on the other hand restricted possibilities to replicate this local concept to other store locations, Ertl/Renz and the 3D scanning specialist corpus.e [Rutschmann, Josten, 2003] started to overcome these constraints by forming a concept and technologies under the brand name "a misura" to industrialize the supply of individualized ski boots. 


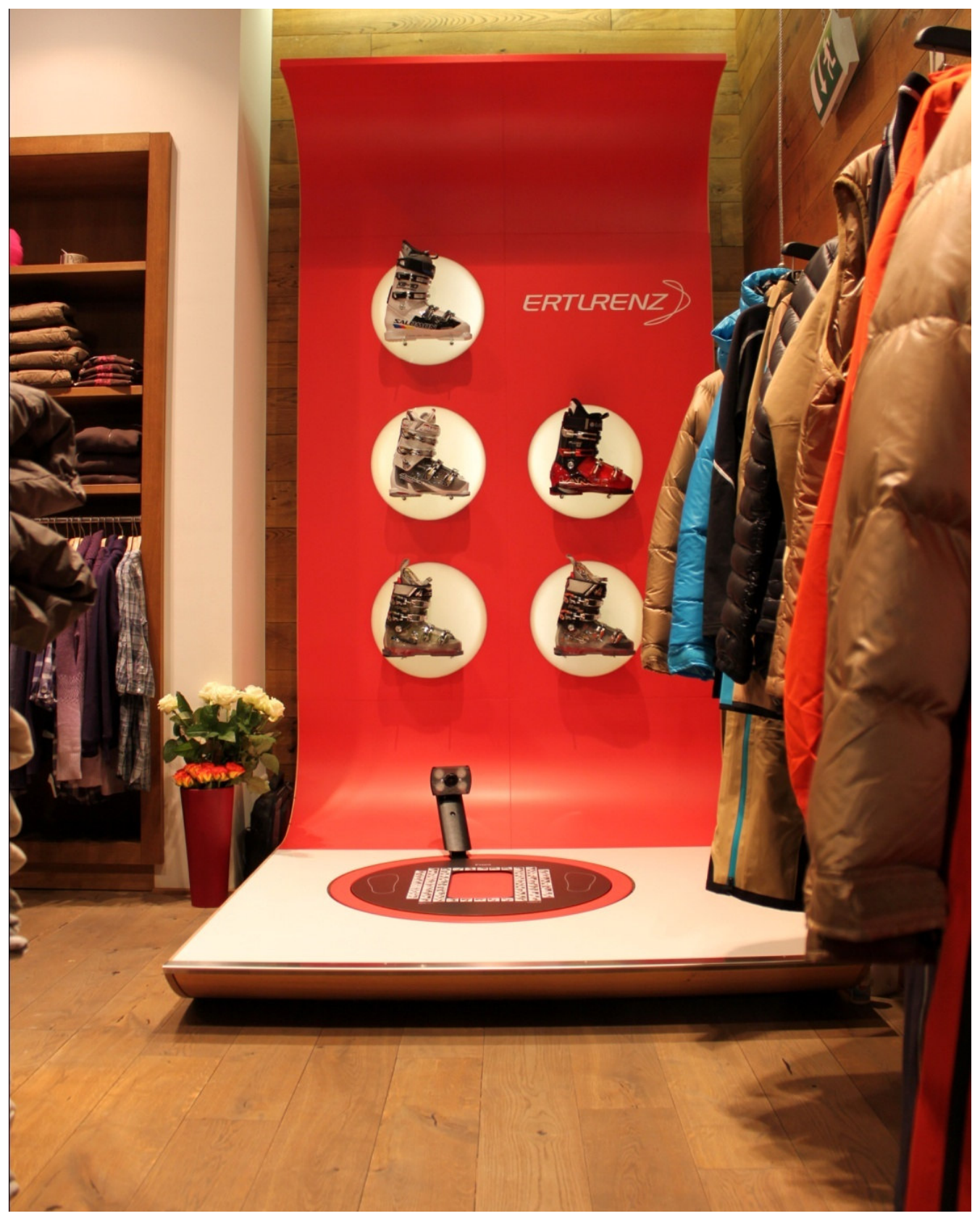

Figure 1: ERTLRENZ Shop-in-Shop System for customized Shoes

This concept was tested three years ago starting in the flagship store by dividing the customization process into the parts with consumer interaction and the production and delivery of the customized product. Before that the gathering of customer relevant information like skiing type or foot measurements was not standardized because often one person was responsible for the whole process and therefore there was no need to transfer the information between the employees or locations. We then built up a standard procedure starting with a short survey with a few questions to ask the customer followed by a 3D footscan with an integrated pressure sensor. This information is then stored in a Customer Relationship Management (CRM) System combined with remarks of the sales person. We also developed the possibility to make a 3D scan of the inside of shoes because the suppliers of the standard ski boots are not willing or able to give out the exact measures of the ski boot. All these 3D measurements of the shoes are stored in a database and the sales staff could find the best matching standard boot by clicking on one button letting the internet based matching engine find the geometrical best fit between the 3D footscan and a shoe from the database. This fit is then be visualized to the customer who can see now how his foot will fit inside of the suggested ski boot like an $x$-ray. The sales professional could then exactly explain why or why not this standard product is fitting and what could be improved by customizing the shoe. 


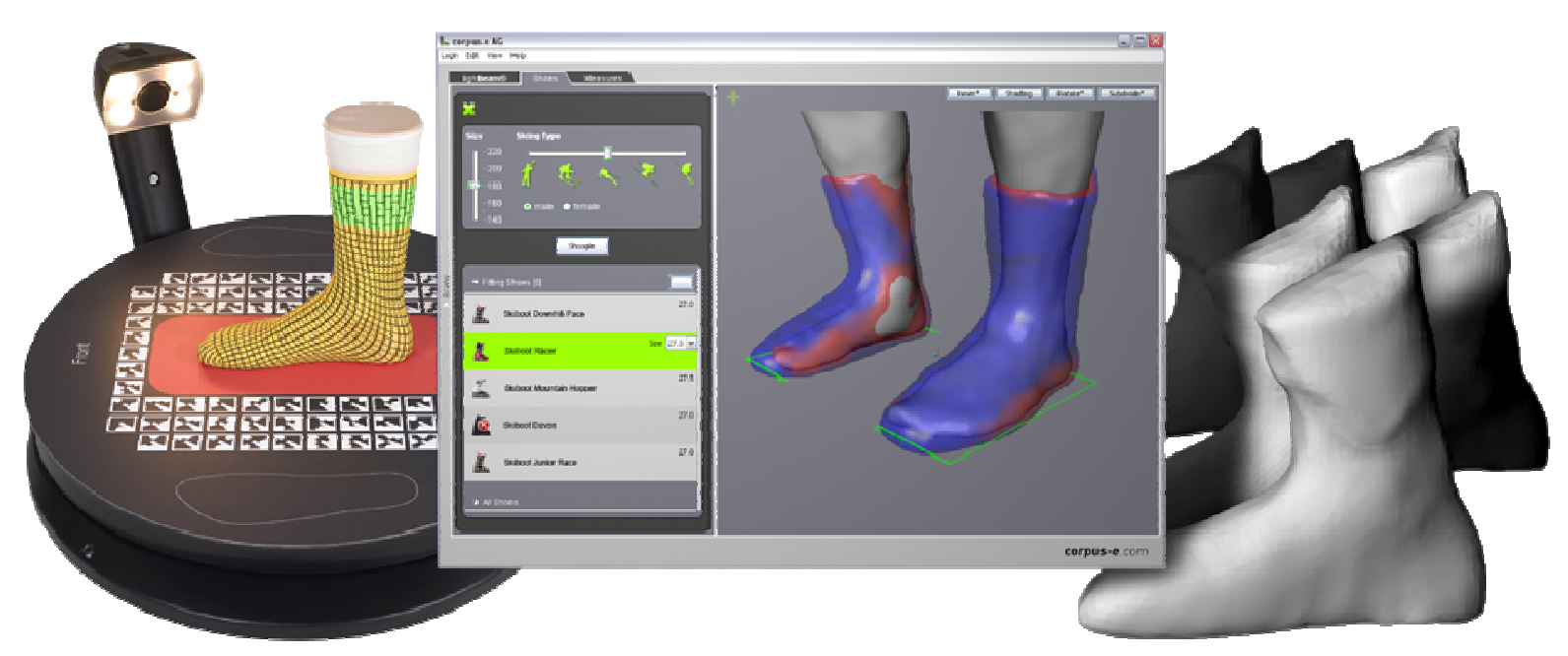

Figure 2: Best-Fit-Matching based on inside shoe 3D-Scans

If the customer decides to buy the customized ski boot the outer shell will be individualized to the customer's feet by a thermal process. Therefore the former hand crafted production was improved by having the exact inner form or last of every ski boot from the inside shoe scan. With this perfect mold the areas to change for a customer can now be easily changed on the mold and the boot could afterwards be formed to the customer's necessities by pressing the individual mold into the heated outer shell. The whole production process can be conducted based on the information taken in the sales process without the need of the sales staff or the customer again. Also an individual milled insole is modeled and optimized for the customer's mass customized ski boot.

In the winter season in 2009/10 following the above fundamental industrialization of the process two years ago we tested the replication of the processes to different store locations. We've chosen two stores between 100 and $200 \mathrm{~km}$ away from the location of the centralized production. One store was chosen in a skiing area on the northern side of the Alps in Garmisch-Partenkirchen where the World Championships will be in 2011, the other one nearby Stuttgart. Both stores were equipped with a shop-in-shop system with an integrated 3D footscanner, the matching software to find the best fitting standard shoe and the CRM system to collect all the necessary information. After advising the customer and taking the necessary scan measurements and other relevant information the data is automatically transferred via internet to the production site. There the product is customized as described above and the individual customer shoe is delivered back to the store where the customer can pick his product up a few days later.

This shop-in-shop concept was extended in the winter 2009/10 to ten additional locations in Germany and Austria to sell the customized ski boots based on the high quality central production with the knowhow and machinery to deliver a better customization quality than all other hand crafted boot fitters. These stores are located in other major cities of the country and also in notably skiing affine areas around the Alps. We are also preparing to sell on the same technology basis other shoes with a high potential of misfit like hiking, cycling or golf shoes.

\section{Experiences}

We have explicitly chosen ski boots as a type of shoe where one dimension of the additional features of mass customized shoes is important, the fit, and the other new possibility of individual style is not as important. All other shoes which are targeted onto the same platform are all relatively inflexible shoes where the fit to the foot is a fundamental function of this kind of sports equipment. This assortment allows us to keep the complexity of expectations on a lower level.

The most critical part in scaling up this shop-in-shop concept is the point of sales and the staff dealing with the expectations of the customer. On the one hand there is a great need in explaining what kind of 
offer is made with the mass customized ski boots. Therefore we recognize how important visualization technologies for this special kind of sales process are. Because we are able to show on the computer screen how the customer's foot will fit in a mass production standard shell we can also explain very transparently in which areas there are potential fitting problems. The customer understands very clearly what is done then when the boot is customized and for what kind of service the surplus has to be payed.

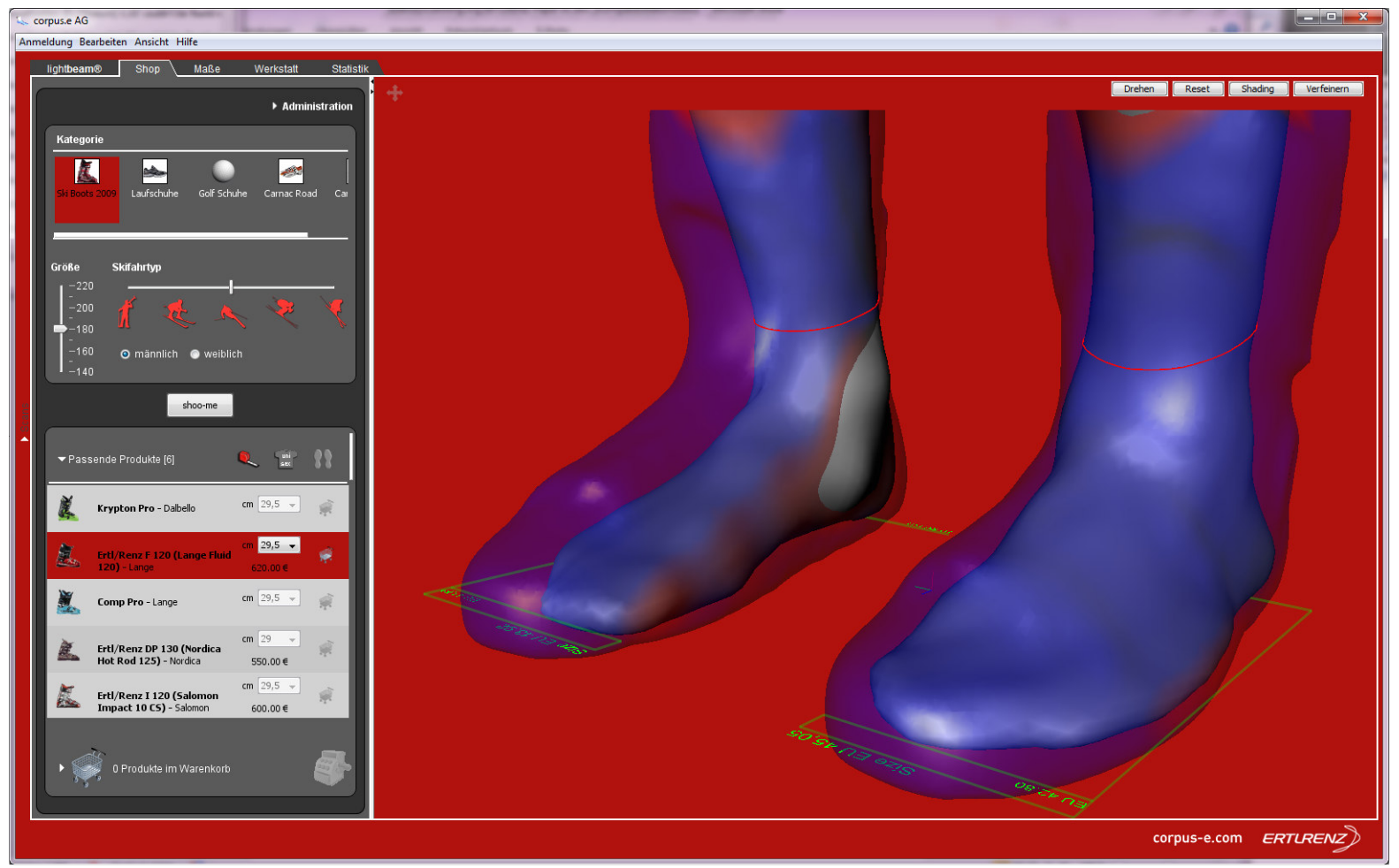

Figure 3: Software to match and simulate the best fitting shoe

What is also a daily experience is that the customer who is unsatisfied with the fit of standard products expects then with this mass customization offer a cushy shoe more like a slipper and not like sports equipment which has to transform the biomechanical power best possible onto the ski. This phenomenon is like giving the customer an inch and he will take an ell. Therefore the quality of the management of expectations at the point of sales is one of the most important and critical parts.

Another experience is the necessary coverage of the sales regions. We've made a survey in the most important german skiing magazine where we've asked the potential customer how many kilometers he is willing to travel to get a high quality customized skiing boot. The outcome was interesting in the way that for this kind of niche product $40-50 \%$ of the customer's are willing to travel up to $250 \mathrm{~km}$. Therefore in this market it could be that there is no need of vast number of sales locations.

Other important factors like price (or surplus) and delivery time - which were subject of several surveys and papers [Piller, 2002] - are varying for this product dependant on the kind of area the shop is located. In locations in skiing areas the typical customer is a guest who arrives in most cases at Saturday and exerts to get the skis as fast as possible onto the slope. In this case the delivery time is one of the key factors. On the other hand there is a high anticipation that in this area the shops have a profound knowledge about the perfect fitting ski boot. Therefore the customer's are often willing to pay a surplus for this service compared to the same offer in other regions. If the shop is not located in the typical skiing areas the customer's are able to manage longer delivery times around one or up to three weeks because they normally have a much longer booking lead time for the accommodation. If the custom fitting ski boot solves the problem of hurting feet the customer's are also willing to pay a surplus for this service to the standard high quality mass production boot (for an average price of 450 EUR) in the area of 100 to 200 EUR (resulting in an average price for the customized product of 650 EUR). 
The breakeven point for the shop-in-shop hardware for a sales point is reached after selling about 150 pairs of ski boots. This is approx. $10 \%$ of the per year sales the flagship store in Munich is selling. The shops are asking for extending the service on other products in other seasons than autumn \& winter and for using the infrastructure also for standard mass products. Therefore the explanation for the customer is much easier if the mass customized is the top product on top of the standard mass products from which the customer can choose as the case arises. The need for fit customization depends on the extend the mass products are covering the customer's foot forms in an adequate way. We experienced in the ski boot area that within about 5.000 scanned customer's there are only about 5 where there is no need for changing the form of the product.

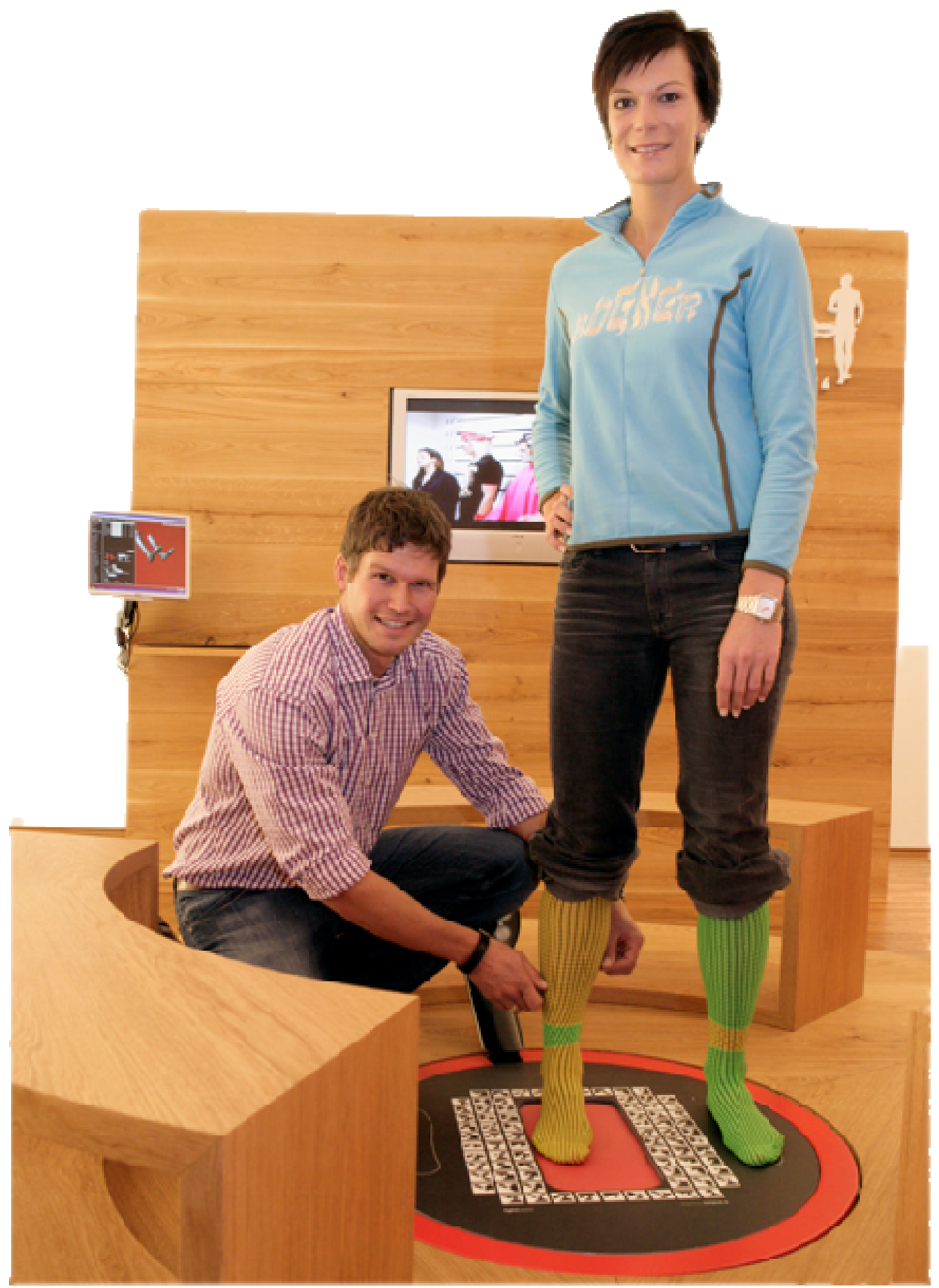

Figure 4: Customizing ski boots for Maria Riesch (2x Olympic gold medal winner Vancouver) 


\section{Conclusion}

In segments of the shoe industry where the fit of a shoe is evident for the functionality of the product and where the shoe is stiff we observe many customer's with problems to find the right product [Luximon/Goonetilleke 2003]. The most common way for mass products is the trial and error method in finding the best fitting shoe with the outcome that normally a too big shoe is chosen to allow to wear the product but resulting in other problems like fewer footholds [Janisse 1992]. In most of the cases small individual changes result in a high customer satisfaction. By supporting the most important interface to the customer, the sales staff, with a high level of visualization tools the customer sees directly and on an objective basis what kind of service he is paying for. In this case the customer is normally willing to pay a surplus for this service and accepting the longer delivery time.

\section{References}

1. Ameersing Luximon and Ravindra S. Goonetilleke (2003): "Dimensions for Fitting Footwear" Proceedings of the IEA 2003 XVth Triennial Congress (August 24-29, 2003) Seoul, Korea

2. Anderson, David M. (2004). "Build-to-Order \& Mass Customization; the Ultimate Supply Chain Management and Lean Manufacturing Strategy for Low-Cost On-Demand Production without Forecasts or Inventory", (2004, CIM Press), ISBN 1-878072-30-7

3. Bor, Claudio, Dulio, Sergio (2007): "Mass Customization and Footwear: Myth, Salvation or Reality?", Springer, ISBN 978-1846288647

4. Dennis J. Janisse (1992): "The Art and Science of Fitting Shoes", in: Foot and Ankle, The American orthopaedic society, p. 257 - 262

5. Piller, Frank (1999): "Mass Customization Newsletter 1 - 1999", http://www.open-innovation.com/news/news99_1.htm

6. Piller, Frank, ed. (2002): "The Market for Customized Footwear in Europe: Market Demand and Consumer Preferences. A project report from the EuroShoe Project within the European Fifth Framework Program".

7. Ravindra S. Goonetilleke, Ameersing Luximon, and Kwok L. Tsui (2000): "The Quality of Footwear Fit: What we know, don't know and should know" in: Proceedings of the IEA 2000/HFES 2000 Congress, pages $2.515-2.518$

8. Rutschmann (2003): "Affordable 3D Scanning for Customizing Ski Boots" World Conference on Mass Customization and Personalization, München, 2003

9. Rutschmann, Josten (2003): "The MagicalSkin Scanner: A radically low cost and mobile 3D scanner for human body parts based both on a new technology and a new business model" 3D Modelling 2003, Harbour Conferences, Paris 2003 